\title{
Human capital in rural areas of the Chelyabinsk region
}

\author{
Ekaterina Abilova, ${ }^{1, *}$ and Sergey Golovikhin ${ }^{1}$ \\ ${ }^{1}$ Chelyabinsk State University, 129, str. Kashirin brothers, 454001, Chelyabinsk, Russia
}

\begin{abstract}
The significance and scientific novelty of the approach proposed in the article to the peculiarities of human capital formation in rural areas, acceptable for analyzing the current state of this phenomenon and constructing the optimal trajectory of its development, is substantiated, firstly, by taking into account the modern features of rural areas, including their multifunctionality; secondly, by positioning human capital not only as an individual, but also as a social phenomenon; thirdly, by integrating into the concept of such characteristics of human capital in rural areas as its relativity (network nature) and cumulativeness ( possibility of accumulation within territorial boundaries); fourthly, the identification of the human capital of rural areas as a complex adaptive system, spatially localized, associated with other systems, evolving under the influence of factors of micro-, meso-, macro-levels. The article discusses the concept of human capital in the context of rural areas and identifies their features. A logical scheme for the study of the peculiarities of the formation of human capital of agricultural business entities is proposed.
\end{abstract}

\section{Introduction}

Conceptualization of the phenomenon of human capital (as one of the components of the resource potential of industries and territories) has been in the focus of attention of domestic and foreign representatives of economic theory for many decades [3]. A comprehensive interdisciplinary methodological approach to the analysis of the human capital of rural areas in various aspects (territorial, sectoral, historical) involves integration of achievements and research tools of a number of popular concepts today, associated, firstly, with the development of human capital in the light of the ongoing rapid changes in engineering, technology, value guidelines, secondly, with the evolution of rural areas in modern environmental conditions, and thirdly, with the need for agricultural regions to achieve high competitiveness, which, in turn, determines harmonious spatial development of the country. With regard to rural areas, the concept of their sustainable development and the concept of their multifunctionality certainly deserve attention [5]. A village is characterized not only by the specificity of production, but also by a special way of life that has been formed over the centuries. An agrarian reform, implemented in a short time, can change the very essence of existence of the rural population and can be rejected by the majority of rural residents.

\footnotetext{
* Corresponding author: ekaterina.abilova@mail.ru
} 
The village as a socio-territorial subsystem of a society is a single socio-economic, territorial, natural and historical-cultural complex, constituent parts of which are the rural population [4], the totality of social relations associated with its life, the territory and the material objects located in it. For this reason, sustainable development of rural areas is the basis for stable development of regions, both economically and socially.

The problem of sustainable development of rural areas is currently one of the key areas of the country's agricultural policy. The solution to this problem is carried out, as a rule, on the basis of implementation of federal and regional targeted programs for social development of the countryside. Today, the most urgent problems are the following: monitoring and analysis of the conditions, processes and results of functioning of human capital [9] in rural areas of domestic regions of various types (agrarian, agrarian-industrial, industrial); identification of potential trends in changing conditions for the formation and development of human capital in rural areas, taking into account the changing system of social values, global trends, national policy priorities, social preferences, environmental (and other) challenges and other circumstances; forecasting the development of human capital in rural areas (by testing the proposed methods) in the regions of the Ural Federal District, whose rural areas are significantly differentiated by industry specialization, level of scientific and technological development and infrastructure development, indicators of socio-economic dynamics; determination of directions and instruments of state support for the development of human capital in rural areas, development of methods for assessing its effectiveness.

\section{Materials and methods}

It is known that economic progress is significantly influenced by various factors, including social ones. At the same time, it is based on the effective use of basic economic resources in a certain cultural and social context (labor, land, capital and entrepreneurship). As for the development of rural areas, this process can be interpreted as a permanent movement leading to an increase in the results of the functioning of the agricultural sector, on the one hand [16], and ensuring high social and environmental living standards in rural areas, on the other. At the same time, agricultural activity as a leading form of production in rural areas, developing in a multiplication manner, should (according to most researchers) automatically stimulate the solution of emerging social and environmental problems. Nevertheless, the theory and practice of rural development proved that the previous basic concepts of development in solving this issue do not correspond to the real situation [7], and the most important problems of preserving a fragile ecosystem and overcoming the existing inequality between population groups (rural and urban), regions within the country (agricultural and industrial), in fact, cannot be solved within the framework of the currently dominant theoretical structure.

As a result, the agricultural policy of Russia (like many other countries) is aimed today not only at improving production, but also at creating conditions for the development of a harmonious personality, reproduction of a favorable human living environment [1], development of rural areas, preservation of the national and cultural identity of rural communities, while a few years ago it focused exclusively on the production aspects of agriculture as a leading sector of the economy. In this regard, there is a need for new scientific approaches to the use of traditional economic resources and the conceptualization of production factors importance of which is growing in the modern science for quite objective reasons.

The purpose of this study is to develop an approach to the peculiarities of the formation of human capital in rural areas in Chelyabinsk region, taking into account, firstly, modern prospects for development of rural areas (agrarian regions) in the context of their 
multifunctionality and the need for sustainable, dynamic and balanced development, and secondly, new vision of human capital itself as a complex network structure evolving under the influence of factors of micro-, meso-, macro-levels. Chelyabinsk region has a powerful production, intellectual and natural potential necessary to ensure the effective functioning of the regional economic system, the dynamic development of all sectors of its national economy, and the improvement of the welfare of citizens [12]. The elimination of significant differences between the city and the countryside, the transformation of historically established rural settlements into modern agro-towns and villages with a high level of amenities, cultural, household and communal services is one of the most important directions of the state policy of Chelyabinsk region.

The regional target programs "Development of agriculture in Chelyabinsk region for 2016-2020" and "Sustainable development of rural areas of Chelyabinsk region for 2014$2020 "$ explicitly say about the need to ensure sustainable development of rural areas. The state program "Comprehensive Development of Rural Areas" is aimed at overcoming such crisis phenomena in rural areas as poverty, unfavorable demographic situation, uncontrolled migration, stagnation of agricultural production, depreciation of fixed assets, etc.

The problem of effectively solving the issues of social development of the countryside in modern Russian society is particularly significant. Russia is going through a severe crisis in the social sphere. An assessment of the socio-economic situation in Chelyabinsk region indicates the fact that we are rather dealing with an unbalanced social sphere and agerelated social tension than with a crisis.

\section{Results}

Since the human capital of a rural area has certain characteristics, formed due to the interaction and mutual influence of various (unique, inherent in rural areas) elements of the regional system (economic, social, infrastructural, etc.), when assessing its state it is necessary, firstly, to study the trends observed in such sectors as education $[11,8]$, health care, culture (the state of these particular areas determines the possibility of formation, development and use of human capital); secondly, to highlight the impact on the economic development of rural areas of such a leading industry as Agriculture. At the same time, it is important to assess, on the one hand, the impact of the socio-economic development of the region on dynamics of the state of its human capital, on the other hand, the possibilities of human capital in the development of rural areas (including potential ones). In general, the hypothesis is that the more successful a region is in terms of socio-economic indicators, the more attractive it becomes for highly qualified specialists who ensure not only a sufficient level of development of an agricultural sector, but also a decent level of functioning of education, health care, culture, various branches of the service sector necessary for a decent living [6]. On the other hand, concentration of specialists of a wide range of professions on the territory of the region ensures innovative development of the region, the formation and positive dynamics of a full-fledged regional agri-food cluster.

For further monitoring and analysis of the conditions, content and results of functioning of the human capital of rural areas of domestic regions of various types (agrarian, agroindustrial, industrial), it will be necessary to take into account such features of the territories as the spatial organization of production within the region, the existing settlement system, and promising economic specialization, the possibility of forming centers of economic growth, the spatial availability of services, the available resource (in addition to human capital) potential, the availability and condition of engineering, transport, and social infrastructure. 
Table 1. Some indicators of social development of Chelyabinsk region.

\begin{tabular}{|l|c|c|c|c|c|}
\hline \multicolumn{1}{|c|}{ Indicator } & $\mathbf{1 9 9 0}$ & $\mathbf{2 0 0 0}$ & $\mathbf{2 0 1 0}$ & $\mathbf{2 0 1 7}$ & $\mathbf{2 0 1 8}$ \\
\hline $\begin{array}{l}\text { Total area of residential } \\
\text { premises on average per 1 } \\
\text { resident. sq. m }\end{array}$ & 18.5 & 20.0 & 23.0 & 25.8 & 26.4 \\
\hline urban area & 18.8 & 20.8 & 22.8 & 25.4 & 26.0 \\
\hline countryside & 17.6 & 19.8 & 23.8 & 27.8 & 28.6 \\
\hline $\begin{array}{l}\text { Number of preschool } \\
\text { institutions }\end{array}$ & 1200 & 1170 & 1225 & 1240 & 1243 \\
\hline urban area & 607 & 595 & 613 & 625 & 627 \\
\hline countryside & 593 & 575 & 612 & 615 & 616 \\
\hline $\begin{array}{l}\text { Number of daytime general } \\
\text { education institutions }\end{array}$ & 1070 & 1407 & 1802 & 2274 & 2389 \\
\hline urban area & 839 & 955 & 1269 & 1683 & 1736 \\
\hline countryside & 231 & 452 & 533 & 591 & 653 \\
\hline $\begin{array}{l}\text { The number of nursing staff per } \\
10.000 \text { population }\end{array}$ & 38.1 & 39.3 & 43.0 & 42.5 & 42.0 \\
\hline $\begin{array}{l}\text { Capacity of outpatient and } \\
\text { polyclinic institutions. visits per } \\
10.000 \text { population }\end{array}$ & 252.3 & 265.9 & 288.6 & 315.5 & 320.1 \\
\hline
\end{tabular}

Without active measures for social development, it is impossible to overcome the situation when the village remains in debt, essentially outside the process of transition to a new economic system. In fact, the ultimate goal of the reform is the creation of an economic system based on economic interests, ensuring the growth of production efficiency due to the competition of free producers [10]. Enterprises whose property is heavily burdened with debts can no longer act as full-fledged participants in the market turnover.

In such conditions, the burden of social reconstruction of the countryside should be born by the state. At least - its main part. Of course, investments in the village should pay off [2]. Moreover, first of all, investments are needed that can expand bottlenecks and give a quick return. This is, first of all, the costs of processing agricultural products, creation of production infrastructure in the village, creation of sustainable rural areas. As for the social infrastructure of a village, the return on investment here takes a long time [15]. Therefore, it is advisable to finance the main part of the commissioning of schools, hospitals, clubs, gasification facilities, roads from the budget.

The development of medical services in the countryside should be subordinated to the task of preserving the existing health potential of the population and increasing it. This presupposes the creation of a specialized subsystem within the unified health care system focused on the specific tasks of protecting the health of villagers. Among the negative demographic processes taking place in rural areas, there is a decrease in the population size associated, firstly, with the migration of young people to the city, secondly, with a decrease in the birth rate, and thirdly, with a higher mortality rate in the countryside compared to urban population [2]. The reasons for the crisis in the demographic situation in rural areas are changes in reproductive behavior in connection with the restructuring of the structure of values, a decrease in the level and quality of life of a significant part of the population, the socio-demographic reaction of families, and changes in the reproductive attitudes of rural families. This gives the problem of human capital development in rural areas the significance of the subject of national security in all its components: political, economic, state.

In the course of the study, the basic postulates of an integrated approach to the essence, analysis and forecasting of the development of human capital in rural areas were formulated, taking into account the following: the prevailing features of human capital itself, trends in the development of rural areas, the tasks and national priorities of the 
Russian Federation, defined in strategic planning documents related to sustainable, dynamic , balanced development of the country and its rural areas. Trends and alternative trends in the development of peasant (farmer) households in the changing socio-economic and political environment have been identified [17]. The transition to a market economy causes changes in social relations. The dynamism of the development of society, the new commodity-money nature of the emerging production relations are the main reason for the need to change the state policy in the field of education.

\section{Conclusion}

Today we consider a village as a whole system of interrelated components, including historical, economic, social, territorial and natural aspects. The central link of this system is the villagers, with their characteristic way of social relations, ensuring the principles of life, the rural area with infrastructure facilities. A progressive vision of sustainable development of rural areas lies in the fundamental postulates of social and economic development of the regions. Therefore, it is necessary to develop and test a comprehensive interdisciplinary model of the human potential of rural areas, taking into account the modern prospects for the development of the countryside (agricultural regions) in the context of their multifunctionality and the need for sustainable, dynamic and balanced development [14]. The problem of sustainable development of rural areas is currently one of the key parameters for the development of the country's agricultural policy. The solution to this problem is carried out, as a rule, on the basis of implementation of federal and regional targeted programs for the social development of the countryside.

\section{Acknowledgement}

The study was carried out with the financial support of the Russian Foundation for Basic Research (project No. 19-29-07315).

\section{References}

1. M. Ahmad, M.M.C. Allen, M.M. Raziq, W. ur Rehman, Employee Relations 41(5), 931- 948 (2019) doi.org/10.1108/ER-01-2018-0021

2. A. Al Ariss, Y. Sidani, Human Resource Management Review 26(4), 283- 284 (2016) doi.org/10.1016/j.hrmr.2016.04.001

3. J. Anderson, National Survey and Segmentation of Smallholder Households in Mozambique: Household Level Data (CGAP, Washington, DC, 2019)

4. P.S. Budhwar, V. Pereira, K. Mellahi, S.K. Singh, Asia Pacific Journal of Management 36(4), 905- 933 (2019) doi.org/10.1007/s10490-018-9587-7

5. A.J. Cannon, Climate Dynamics 50(1-2), 31- 49 (2018) doi.org/10.1007/s00382-0173580-6

6. Z. Chen, G.N. Powell, J.H. Greenhaus, Journal of Vocational Behavior 74(1), 82-93 (2009)

7. L.T. Eby, W.J. Casper, A. Lockwood, C. Bordeaux, A. Brinley, Journal of Vocational Behavior 66(1), 124-197 (2005)

8. E. Farndale, I. Nikandrou, L. Panayotopoulou, Handbook of research on comparative human resource management (2018) doi.org/10.4337/9781784711139.00014

9. G.S. Gomes, Journal of Agriculture Science and Technology A10, 147-150 (2020) 
doi:10.17265/2161-6256/2020.03.005

10. P. Gooderham, M. Fenton-O'Creevy, R. Croucher, M. Brookes, Journal of Management 44(4), 1479- 1504 (2015) doi.org/10.1177/0149206315610634

11. Y. Kim, R.E. Ployhart, Academy of Management Journal 61(1), 46-66 (2018) doi.org/10.5465/amj.2015.0811

12. C. Miyata, N. Minot, D. Hu, World Dev. 37, 1781-1790 (2009)

13. D. Pletnev, M. Kazadayev, V. Barkhatov, E3S Web Conf. (Key Trends in Transportation Innovation (KTTI-2019)) 157, $04028 \quad$ (2020) https://doi.org/10.1051/e3sconf/202015704028

14. D. Pletnev, E. Nikolaeva, Country Experiences in Economic Development, Management and Entrepreneurship. Eurasian Studies in Business and Economics, Springer, Cham 5, 443-452 (2017) https://doi.org/10.1007/978-3-319-46319-3_27

15. E. Poutsma, P.E.M. Ligthart, U. Veersma, Industrial Relations 45(4), $513-546$ (2006) doi.org/10.1111/j.1468-232X.2006.00442.x

16. I. Weller, B. Gerhart, Handbook of research on comparative human resource management (Edward Elgar, 2018)

17. M.A. Youndt, M. Subramaniam, S.A. Snell, Journal of Management Studies 41(2), 335-361 (2004) doi.org/10.1111/j.1467-6486.2004.00435.x 